\title{
Geopolymer Cement: an Initiative towards the Replacement of Grey Cement by Green Cement in Future
}

\author{
Mukesh Kumar M *, Asis Kumar K \\ Dalmia Cement Research Centre, Research Unit of Dalmia Cement Bharat Ltd. Chennai-600116, \\ Tamilnadu, India. \\ * Corresponding Author: mishra.mukesh1@dalmiacement.com
}

Received: 23-10-2020

Accepted: 06-01-2021

\begin{abstract}
The emissions of greenhouse gases such as carbon dioxide from the production of Ordinary Portland Cement and Blended Portland Cement have widely affected the environment with increase in infrastructure development worldwide. Secondly, due to the continuous mining of limestone for the production of cement there is also simultaneous depletion of natural resources and hardly will it last up to maximum 40 years. Hence we need to switch over to some other alternate binders for constructions purpose in future. Geopolymer Cement is one of the inventions which is produced by a polymeric chain reaction of alkali-activated alumino-silicate materials better known as alkali activator $\left(\mathrm{NaOH} / \mathrm{Na}_{2} \mathrm{SiO}_{3}\right)$ binders with the industrial by-product materials such as Fly Ash, Rice Husk Ash, Slag, Crusher Dust etc. and provides high compressive strength which is comparable to $\mathrm{BPC}$ and reduces the carbon foot print. The objective of our study is to prepare the low $\mathrm{CO}_{2}$ foot print green Geopolymer Cement which may substitute the Ordinary Portland Cement and Blended Portland Cement in future and will helpful to reduce the greenhouse effect up to some extent and takes an initiative towards the green revolution movement.
\end{abstract}

Key words: Geopolymer Cement, Green Cement, Carbon Foot Print, Green Revolution, Alkali Activator.

\section{Introduction}

The emission of greenhouse gases such as carbon dioxide $\left(\mathrm{CO}_{2}\right)$ from Ordinary Portland Cement (OPC) and Blended Portland Cement (BPC) production have widely affected the environment with increase in infrastructure development worldwide due to which the production/ demand of OPC as binder in concrete continuously increases (Petek et al., 2014). Due to the natural resource depletion and $\mathrm{CO}_{2}$ emission issues during cement manufacturing, the need of switch over to alternate binders becomes important (Deb et al., 2014). However, the alternate binding materials, those replace the OPC/BPC should have certain criteria such as they should be ecofriendly, acceptable, readily available and cost effective. The durability and strength of the set mass needs to be as good as that from OPC or BPC. Geopolymer Cement (GPC) is one of the least carbon foot print cement which is mainly produced by a polymeric chain of reaction of alkaliactivated alumino-silicate mineral binder (combination of sodium silicate, and sodium hydroxide) with aluminosilicate rich industrial by-products such as Fly Ash (FA)/Crusher Dust (CD)/ Blast Furnace Slag (BFS)/Granulated Blast Furnace Slag (GBFS)/Ground Granulated Blast Furnace Slag (GGBFS)/ Ultrafine Ground Granulated Blast Furnace Slag (UGGBFS) (Laskar et al., 2017 and Part et al., 2015).

The term geopolymer was introduced nearly before two to three decades back by Davidovits (1989) and according to him geopolymers are consist of a polymeric Si-O-Al framework, having amorphous structure. They comprise of small aluminosilicate clusters with pores dispersed within a highly porous network having clusters sizes in between 5 and 10 nanometers. Basically geo-polymers are classified into three types based on their different monomer units such as polysialate $(-\mathrm{Si}-\mathrm{O}-\mathrm{Al}-\mathrm{O}-)$ having $\mathrm{SiO}_{2} / \mathrm{Al}_{2} \mathrm{O}_{3}=2$, polysialatesiloxo $(-\mathrm{Si}-\mathrm{O}-\mathrm{Al}-\mathrm{O}-\mathrm{Si}-\mathrm{O}-)$ having $\mathrm{SiO}_{2} / \mathrm{Al}_{2} \mathrm{O}_{3}=4$, and polysialatedisiloxo (-Si-O-Al-O- $\mathrm{Si}-\mathrm{O}-\mathrm{Si}-\mathrm{O}-$ ) having $\mathrm{SiO}_{2} / \mathrm{Al}_{2} \mathrm{O}_{3}=6$. The alkaline solution dissolves $\mathrm{Al}^{3+}$ and $\mathrm{Si}^{4+}$ ions from the aluminosilicate rich materials, which subsequently improves compressive strength by forming sodium aluminosilicate hydrate 
(NASH) and/or potassium alumino silicate (KASH) gels (Phoo-ngernkham et al., 2015). These are also called as inorganic polymer cement (Palomo et al., 2003) and play vital role in the context of sustainability and environmental issues by reducing the $\mathrm{CO}_{2}$ emissions originate from the manufacturing of Portland cement (Bell et al., 2008 and Shi et al., 2011) because approximately $5 \%$ of global $\mathrm{CO}_{2}$ emissions are originated from the manufacturing of Portland cement (Lawrence et al., 1998 and Hardjito et al., 2004). FA is found to be one of the major sources of silica $\left(\mathrm{SiO}_{2}\right)$ and alumina $\left(\mathrm{Al}_{2} \mathrm{O}_{3}\right)$ in GP. FA is classified to Class C/Class $\mathrm{F}$ based on its chemical composition, where the main difference is the calcium amount. The Class C FA has a higher content of calcium than that of Class F FA. A higher content of $\mathrm{CaO}$ in the FA results in a higher compressive strength of GPC due to the formation of hydrated products, such as calcium silicate hydrate (CSH) (Diaz et al., 2010). However, at this condition workability of GPC is found to be decreasing significantly (less than $3 \mathrm{~min}$ ) due to high reactivity of Class C FA. Hence, Class F FA is selected as a good raw material for GPC due to its lower reactivity rate, which leads to a proper workability and reduced water demand (Kumar et al., 2010). In order to improve the mechanical properties of GPC made up of class F FA, small amounts of other additives enriched in $\mathrm{CaO}$ such as BFS can be added (Kim et al., 2013). The GGBFS is one of the most common components in geopolymer mortar and concrete, due to improved mechanical and micro structural properties (Hubler et al. 2011).

GPC may be treated as an alternative to Portland Cement (PC), with an improved performance compared to traditional concretes (Van Jaarsveld et al., 2002 and Hardjito et al., 2004] while utilizing a suitable proportion of by-product materials. When developing GPC formulations, the type, amount and ratio of the raw materials, curing time and temperature needs to be taken into account (Part et al., 2015). BFS based GPC have wide range of potential applications as they may replace the conventional Portland Cement Concrete (PCC) in the construction industry. The use of GPC can reduce the $\mathrm{CO}_{2}$ emission which is produced due to the manufacturing of PC. Zhang et al. in 2003 had summarized the discussions on geopolymer based on previous research and showed that the geopolymer is nothing but a form of zeolite precursor or intermediate (Babajide et al., 2012). Moreover, Hu et al. (2008) had investigated the compressive strength, bond strength and abrasion resistance of metakaolin (MK) based concrete consisting of geopolymer pastes and found that the early strength and mechanical properties were found to be better than that of Portland cement based pastes. Increase in fineness of binding material also leads to early strength gain in GPC because early age strength is a desirable property of concrete repairing agent (Kim et al., 2017).

\section{Materials and Experimental methods}

GBFS, FA and alkali activators $\left(\mathrm{NaOH} / \mathrm{Na}_{2} \mathrm{SiO}_{3}\right)$ are the major raw materials used in this trial. To get proper fineness, both GBFS and FA are ground in $5 \mathrm{~kg}$ capacity lab ball mill at different time interval. R-45 micron sieve residue and fineness (by Blaine air permeability apparatus) are the parameters taken into consideration in the ground slag samples. 1:1 ratio of GBFS and FA are taken into consideration for experimental study and 1:1 ratio mixture of 14 M Sodium hydroxide and liquid Sodium silicate solution are used as alkali activators in this trial. It is because the GPC mixes with $14 \mathrm{M}$ alkali concentration is found to be exhibit higher Compressive Strength (CST) as compared to other lower molar alkali concentration which is in line with the results obtained in earlier studies (Alonso et al., 2001) where the rate of strength gain was explained to be dependent on alkali concentration i.e. lower alkali concentration led to slow rate of formation of polymerization product with lower structural strength (Atis et al., 2015) while higher is the alkali concentration higher will be the rate of strength gain at specified days.

To prepare geopolymer mortars, GBFS and FA are dry mixed in planetary mixer with 1:1 ratio for 60 seconds and $50 \%$ alkali activators solution is added in it and again wet mixed thoroughly for 90 seconds. Mortar casting done in $70 \mathrm{~mm}$ cubical mould, Geopolymer paste is filled in it and

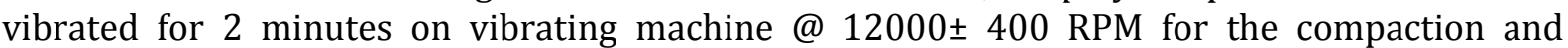


removal of air voids. After 24 hours, mortars are removed from moulds and they have been kept at room temperature $\left(27 \pm 2^{\circ} \mathrm{C}\right)$ and CST tests have been done at the intervals of $1,3,7$ and 28 days.

Table 1. Materials used for geopolymer preparation

\begin{tabular}{|c|c|}
\hline GBFS & $50 \%$ \\
\hline FA & $50 \%$ \\
\hline Alkali Activator & $\mathrm{NaOH}^{\mathrm{Na}} \mathrm{NiO}_{3}(1: 1)$ \\
\hline Alkali Activator : Geopowder (FA+GBFS) & $1: 2$ \\
\hline
\end{tabular}

Table 2. Specific surface area, R-45 and R-90 of Geopowder

\begin{tabular}{|c|c|c|}
\hline \multirow{3}{*}{ Geopowder } & R-45 (\% wt.) & 18.23 \\
\cline { 2 - 3 } & R-90 (\% wt.) & \\
\cline { 2 - 3 } & Specific surface area $\left(\mathrm{m}^{2} / \mathrm{kg}\right)$ & 400 \\
\hline
\end{tabular}

\section{Characterizations}

The structural analysis of the composite films were characterized by the XRD technique using Xray Diffraction Spectrometer (Bruker, D8 Endeavor) with $\mathrm{Cu}-\mathrm{K}_{\alpha}$ radiation $(\lambda=1.54 \AA \overline{\text { }})$ over a wide range of Bragg's angles $\left(8^{0} \leq 2 \theta \leq 70^{\circ}\right)$. The elemental analysis was done by X-ray Fluorescence Spectrometer (PANalytical, Axiox mAX). The morphology of the geopolymer cement was studied by Philips CM 200 Transmission Electron Microscope. The presences of different functional groups present in the composites were confirmed by using the instrument Shimadzu Prestige-21 FTIR spectrometer over a frequency range of 4000-500 $\mathrm{cm}^{-1}$. The CST was measured on different samples at 1, 3, 7 and 28 days using CSTM with a maximum load of 500 $\mathrm{kN}$ and a loading force of $2.8 \mathrm{kN} / \mathrm{s}$.

\section{Results and Discussion}

\subsection{X-ray Fluorescence (XRF) Study}

The elemental analysis of the FA, GBFS, GPC and various Blended Portland Cements such as Portland Pozzolana Cement (PPC), Portland Slag Cement (PSC) and Composite Cement (CC) are carried out by X-ray Fluorescence Spectrometer to know the percentage of elements (in the form of oxides) present in the respective materials and the results are given in Table. 3 .

\begin{tabular}{|c|c|c|c|c|c|c|c|c|c|}
\hline Raw Materials & Oxides \% & $\mathrm{SiO}_{2}$ & $\mathrm{Al}_{2} \mathrm{O}_{3}$ & $\mathrm{Fe}_{2} \mathrm{O}_{3}$ & $\mathrm{CaO}$ & $\mathrm{MgO}$ & $\mathrm{SO}_{3}$ & $\mathrm{~K}_{2} \mathrm{O}$ & $\mathrm{Na}_{2} \mathrm{O}$ \\
\hline \hline FA & Values & 64.14 & 25.84 & 3.76 & 1.81 & 1.10 & 0.06 & 1.56 & 0.10 \\
\hline GBFS & Values & 33.28 & 19.03 & 0.68 & 36.71 & 9.10 & 0.33 & 0.52 & 0.38 \\
\hline GPC & Values & 43.23 & 18.14 & 2.12 & 15.76 & 4.29 & 0.41 & 0.89 & 4.68 \\
\hline PPC & Values & 35.31 & 14.00 & 4.00 & 38.78 & 1.58 & 1.77 & 1.15 & 0.12 \\
\hline PSC & Values & 33 & 10 & 2.00 & 46.00 & 2.37 & 2.15 & 0.32 & 0.40 \\
\hline CC & Values & 25.4 & 6.23 & 3.21 & 55.12 & 2.7 & 2.82 & 1.12 & 0.35 \\
\hline
\end{tabular}

\subsection{Mineralogy study by X-ray Diffraction (XRD)}

The XRD pattern of GPC containing GBFS, FA and alkali activator is shown in Figure-1. It is observed from the graph that there are mainly four types of phases such as Mullite (M), Quartz

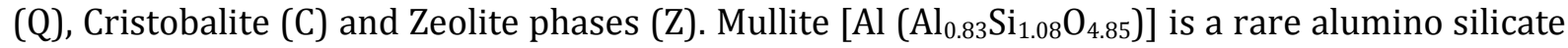
mineral which is formed by post-clay genesis at elevated temperature and atmospheric pressure by a series of reactions in clay minerals (Rashad et al., 2020). The initial endothermic reaction is caused by dehydroxylation of the clay mineral and formation of an amorphous metakaolin phase followed by successive exothermic reactions. The Mullite is signified by Powder Diffraction File 
(PDF no. 01-79-1453), Joint Committee on Powder Diffraction Standards (JCPDS). Quartz is one of the most common minerals in the Earth's crust. It is widely distributed mineral of many varieties which consist of mainly oxygen and silicon having a specific crystalline form (hexagonal) (Huang et al., 2020). The Quartz is signified by (Powder Diffraction File (PDF) no. 00-005-0490. Cristobalite is a mineral polymorph of silica which is formed at very hightemperature in which the silica tetrahedra are packed in a three-layer structure (Qiao et al., 2019). Zeolite, any member of a family of hydrated aluminosilicate minerals that contain alkali and alkaline-earth metals. They are known for their lability toward ion-exchange and reversible dehydration (Nikolov et al., 2020). The formation of Zeolite phase [ $\mathrm{Na}_{8.86}\left(\left(\mathrm{Al}_{8.38} \mathrm{Si}_{27.62}\right) \mathrm{O}_{72}\right]$ indicates that the Mullite, Cristobalite and Quartz phases found in GBFS and FA may be dissolved partly by the binding agent $\left(\mathrm{NaOH} / \mathrm{Na}_{2} \mathrm{SiO}_{3}\right)$ and solidified into $\mathrm{Na}$-Al-silicates which might be a possibility of formation of geopolymer via polymerization reaction. The presence of Zeolite phase is responsible for the higher compressive strengths of GPC.

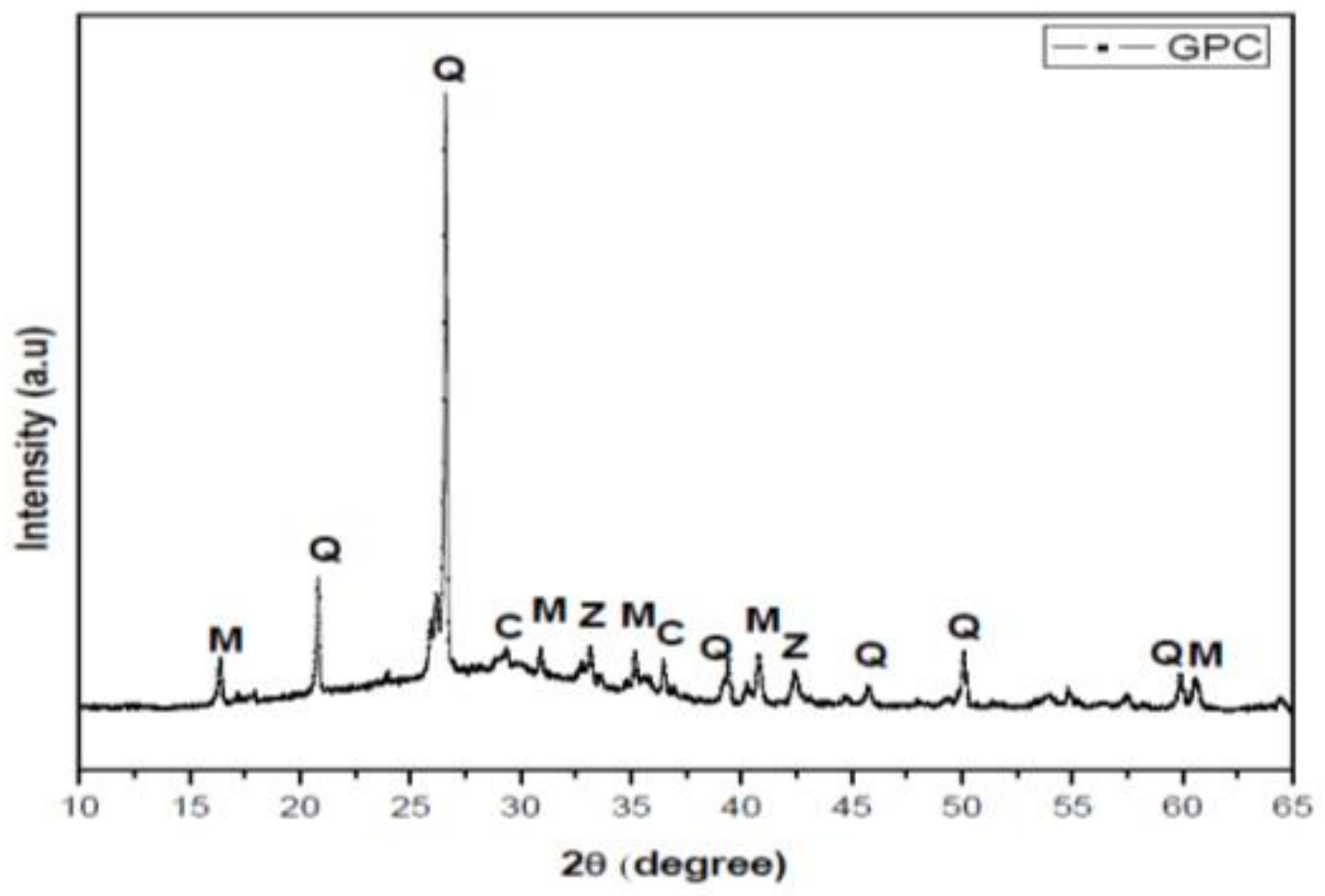

Fig. 1. XRD image of GPC

\subsection{Morphology analysis by Transmission Electron Microscope (TEM)}

Figure- 2 shows the TEM images corresponding to the morphological prospective view of GP with FA and GBFS in 1 day and 28 days. It is observed from both the figure that there are some angular to spherical particles present which could be the polymerization product after treating of FA and GBFS with alkali the activator $\mathrm{NaOH} / \mathrm{Na}_{2} \mathrm{SiO}_{3}$. The morphological changes observed in the GP are due to the suspension of $\mathrm{SiO}_{2}$ and $\mathrm{Al}_{2} \mathrm{O}_{3}$ in alkaline solution leading to the formation of alumino-silicate gel which acts as a precursor during the formation of geopolymer. However, if we observe both figures noticeably it is found that compactness and uniformities of GBFS and FA are low in case of Fig. 2 (a) but they are properly compacted and homogenized in Fig. 2 (b) due to which the CST is higher in 28 days as described by Kumar et al. (2005) due to the formation of a compact microstructure. 




1 day

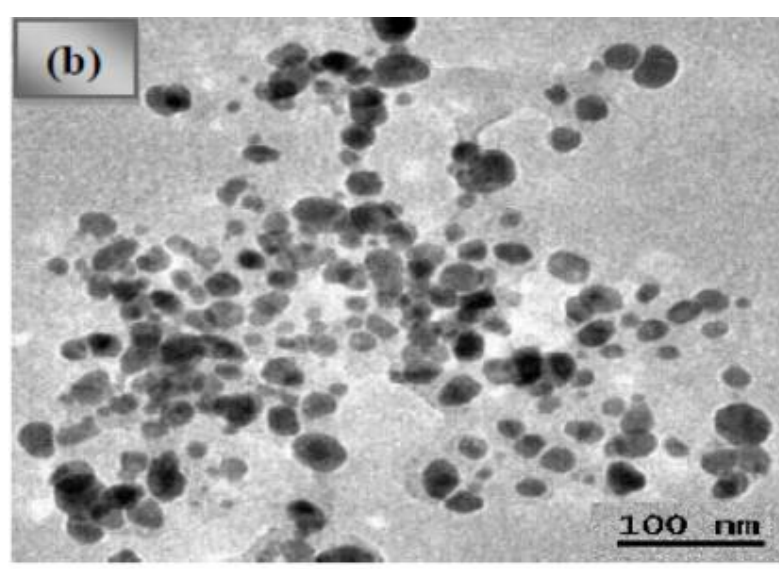

28days

Fig. 2. GPC with FA and GBFS

\subsection{Fourier-transform infrared spectroscopy (FTIR) Analysis}

In case of FA based GPC a peak is observed nearly at $3500 \mathrm{~cm}^{-1}$ corresponding to $\mathrm{O}-\mathrm{H}_{\text {str }}$ which may be due to the addition of small amount of water to the alumino silicates materials (FA/GBFS) along with the alkali $(\mathrm{NaOH})$ and alkali activator $\left(\mathrm{Na}_{2} \mathrm{SiO}_{3}\right)$. The peaks at 1009 and $1034 \mathrm{~cm}^{-1}$ are attributed to asymmetric stretching of $\mathrm{Al}-\mathrm{O}$ and $\mathrm{Si}-\mathrm{O}$ bonds originated from individual tetrahedral. The peak observed at nearly $1000-1100 \mathrm{~cm}^{-1}$ corresponds to $\mathrm{Si}-\mathrm{O}_{\text {str }}$ and this may be due to the formation of (-Si-O-Al-O-) linkage by the polycondensation reactions between the alumino silicates rich materials and alkaline solution (Rajan et al., 2020).

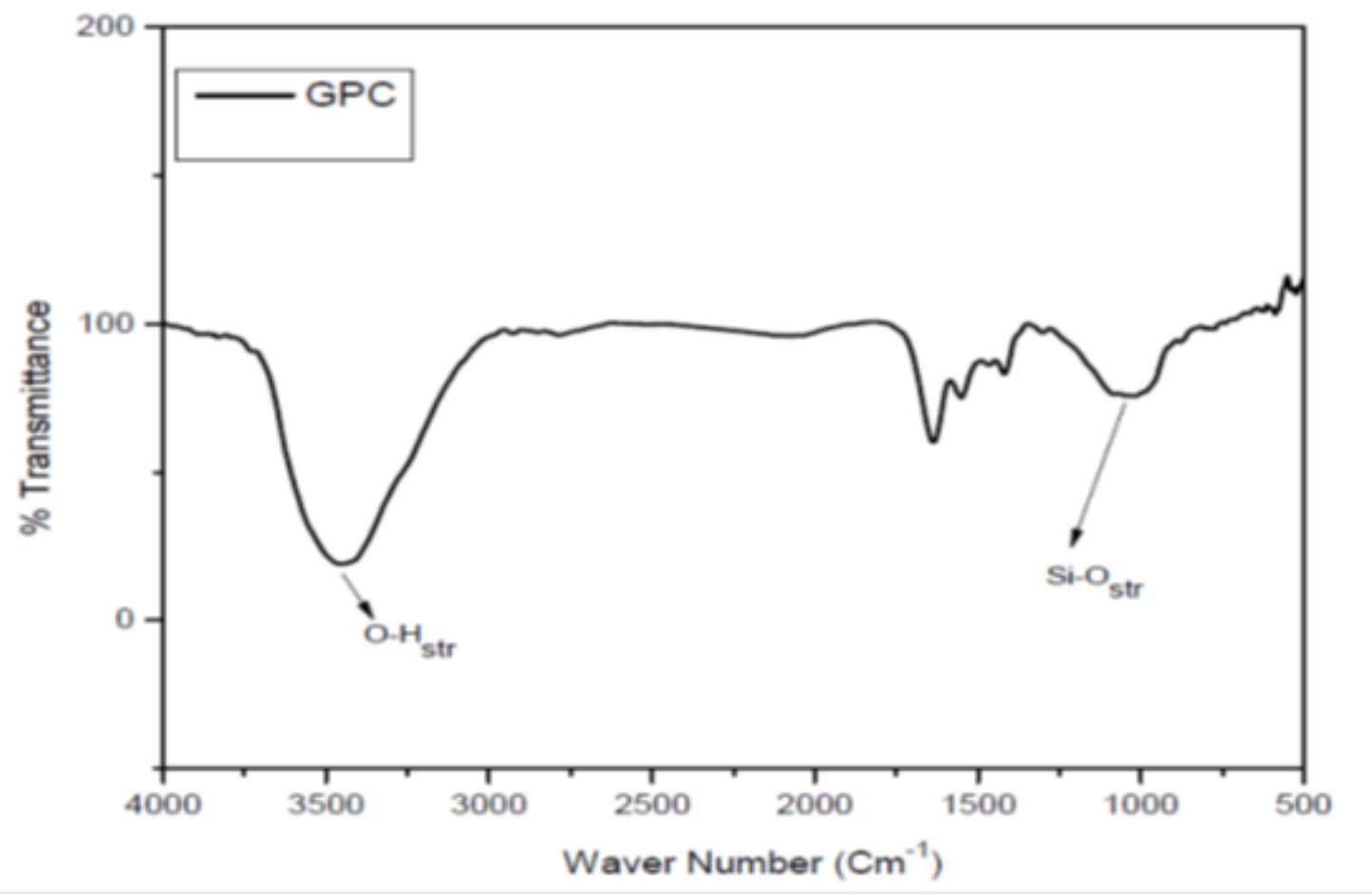

Fig. 3. FTIR Spectra of GPC

\subsection{Compressive strength (CST) of GPC in comparison to other types of BPCS}

CST is a parameter which is used to describe the mechanical properties of cement and concrete. The results of CST of GPC, Portland Pozzolana Cement (PPC), Portland Slag Cement (PSC) and Composite Cement (CC) are given in Figure-4. The CST was found to be increased significantly 
from day 3 to day 28. Similarly the CST of the GPC mixture increases with curing time because the long curing time duration relatively improves the mobility of particles in the mixes leading to their even distribution and thus forming of homogenous mixes and helps to form more compact microstructure of the binder and improving the microstructure of geopolymer matrix (Kosmatka et al., 2002). Secondly, the $\mathrm{Na}$ released from the alkali activator $\left(\mathrm{NaOH} / \mathrm{Na}_{2} \mathrm{SiO}_{3}\right)$ binders during this period would react with the dissolved silicate from the BFS forming new reaction products proposed as a Na-A-S-H type product thereby increasing the later strength (Phoo-ngernkham et al., 2015). However, the strength is low at initial period of time which may be attributed to the less reactivity of $\mathrm{NaOH}$ in the binder and reduced activation of the binder material. This means when the time duration increases the compatibility between the alkali activator and the geopowder (FA+GBFS) also increases which improves their chemical bonding making it more uniform and homogenized and responsible for high compressive strength (Kosmatka et al., 2002).

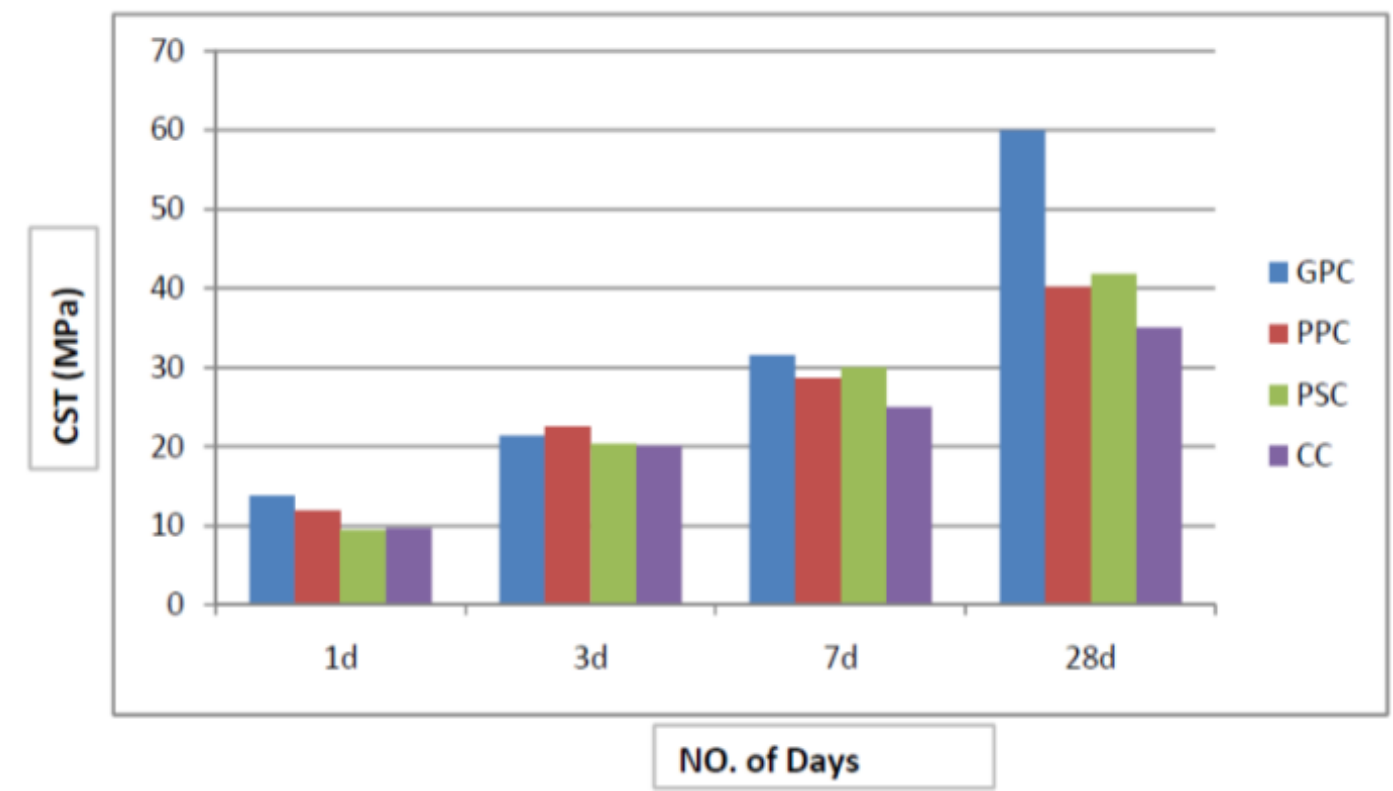

Fig. 4. CST of GPC in comparison to other types of BPCS at the time interval of 1, 3, 7 and 28 days.

\section{Conclusion}

Mixes of GBFS and FA in presence of alkali activators were used for conducting the trials. XRD analysis confirmed the presence of Zeolite phase which is one of the characteristics peaks indicating the formation of geopolymer after the addition of FA and GBFS to alkali activators. TEM indicated the good compactness and uniformities of GBFS \& FA in alkali activators in 28 days. The functional feature of GPC was performed by FTIR. The elemental analysis was done by $\mathrm{XRF}$ spectrometer. The XRD analysis was done to analyze the presence of various phases of GP and GPC. The compressive strength of GPC was found to be higher than that of BPC indicating a good future of GPC which can substitute the BPC for construction purposes and will be responsible for lowering the carbon foot print.

\section{Acknowledgement}

The authors would like to thank Dalmia Cement Bharat Ltd., India for providing all the facilities to carry out the research work and also for the financial support for smooth work. 


\section{References}

Alonso, S., \& Palomo, A. (2001). Alkaline activation of metakaolin and calcium hydroxide mixtures: influence of temperature, activator concentration and solids ratio. Materials Letters, 47(1-2), 55-62.

Atiş, C. D., Görür, E. B., Karahan, O. K. A. N., Bilim, C., İlkentapar, S. E. R. H. A. N., \& Luga, E. (2015). Very high strength $(120 \mathrm{MPa})$ class $\mathrm{F}$ fly ash geopolymer mortar activated at different $\mathrm{NaOH}$ amount, heat curing temperature and heat curing duration. Construction and building materials, 96, 673-678.

Babajide, O., Musyoka, N., Petrik, L., \& Ameer, F. (2012). Novel zeolite Na-X synthesized from fly ash as a heterogeneous catalyst in biodiesel production. Catalysis Today, 190(1), 54-60.

Bell, J. L., Sarin, P., Provis, J. L., Haggerty, R. P., Driemeyer, P. E., Chupas, P. J., van Deventer, J. S. J., \& Kriven, W. M. (2008). Atomic structure of a cesium aluminosilicate geopolymer: a pair distribution function study. Chemistry of Materials, 20(14), 4768-4776.

Davidovits, J. (1989). Geopolymers and geopolymeric materials. Journal of thermal analysis, 35(2), 429441.

Deb, P. S., Nath, P., \& Sarker, P. K. (2014). The effects of ground granulated blast-furnace slag blending with fly ash and activator content on the workability and strength properties of geopolymer concrete cured at ambient temperature. Materials \& Design, 62, 32-39.

Diaz, E. I., Allouche, E. N., \& Eklund, S. (2010). Factors affecting the suitability of fly ash as source material for geopolymers. Fuel, 89(5), 992-996.

Hardjito, D., Wallah, S. E., Sumajouw, D. M., \& Rangan, B. V. (2004). On the development of fly ash-based geopolymer concrete. Materials Journal, 101(6), 467-472.

Hu, S., Wang, H., Zhang, G., \& Ding, Q. (2008). Bonding and abrasion resistance of geopolymeric repair material made with steel slag. Cement and concrete composites, 30(3), 239-244.

Huang, J., Xu, W., Chen, H., \& Xu, G. (2020). Elucidating how ionic adsorption controls the rheological behavior of quartz and cement-quartz paste. Construction and Building Materials, 272, 121957.

Hubler, M. H., Thomas, J. J., \& Jennings, H. M. (2011). Influence of nucleation seeding on the hydration kinetics and compressive strength of alkali activated slag paste. Cement and Concrete Research, 41(8), 842-846.

Kim, J. H., \& Lee, H. S. (2017). Improvement of early strength of cement mortar containing granulated blast furnace slag using industrial byproducts. Materials, 10(9), 1050.

Kim, M. S., Jun, Y., Lee, C., \& Oh, J. E. (2013). Use of CaO as an activator for producing a price-competitive non-cement structural binder using ground granulated blast furnace slag. Cement and concrete research, 54, 208-214.

Kosmatka, S. H., Kerkhoff, B., Panarese, W. C., MacLeod, N. F., \& McGrath, R. J. (2002). Design and Control of Concrete Mixtures, Seventh Canadian Edition, Cement Association of Canada, 151.

Kumar, S., Kumar, R., \& Mehrotra, S. P. (2010). Influence of granulated blast furnace slag on the reaction, structure and properties of fly ash based geopolymer. Journal of materials science, 45(3), 607-615.

Kumar, S., Kumar, R., Alex, T. C., Bandopadhyay, A., \& Mehrotra, S. P. (2005). Effect of mechanically activated fly ash on the properties of geopolymer cement. In Proceedings of the 4th World Congress on Geopolymer (pp. 113-116). 
Laskar, S. M., \& Talukdar, S. (2017). Preparation and tests for workability, compressive and bond strength of ultra-fine slag based geopolymer as concrete repairing agent. Construction and Building Materials, 154, 176-190.

Lawrence, C.D. (1998). The Production of Low-Energy Cements, In: HEWEIT, P, C (Eds.), Lea's. Chemistry of Cement and Concrete, Oxford: Butterworth-Heinemann, 421.

Nikolov, A., Nugteren, H., \& Rostovsky, I. (2020). Optimization of geopolymers based on natural zeolite clinoptilolite by calcination and use of aluminate activators. Construction and Building Materials, 243, 118257.

Palomo, A., \& dela Fuente, J. L. (2003). Alkali-activated cementitous materials: Alternative matrices for the immobilisation of hazardous wastes: Part I. Stabilisation of boron. Cement and Concrete Research, 33(2), 281-288.

Part, W. K., Ramli, M., \& Cheah, C. B. (2015). An overview on the influence of various factors on the properties of geopolymer concrete derived from industrial by-products. Construction and Building Materials, 77, 370-395.

Petek, A. G., Masanet, E., Horvath, A., \& Stadel, A. (2014). Life-cycle inventory analysis of concrete production: A critical review. Cement and Concrete Composites, 51, 38-48.

Phoo-ngernkham, T., Maegawa, A., Mishima, N., Hatanaka, S., \& Chindaprasirt, P. (2015). Effects of sodium hydroxide and sodium silicate solutions on compressive and shear bond strengths of FA-GBFS geopolymer. Construction and Building Materials, 91, 1-8.

Qiao, Z., Liu, Q., Zhang, S., \& Wu, Y. (2019). The mineralogical characteristics between opaline silica in bentonite and $\alpha$-cristobalite. Solid State Sciences, 96, 105948.

Rajan, H. S., \& Kathirvel, P. (2020). Sustainable development of geopolymer binder using sodium silicate synthesized from agricultural waste. Journal of Cleaner Production, 124959.

Rashad, M., Sabu, U., Logesh, G., Srishilan, C., Lodhe, M., Joy, A., \& Balasubramanian, M. (2020). Mullite phase evolution in clay with hydrated or anhydrous AlF3. Journal of the European Ceramic Society, 40(15), 5974-5983.

Shi, C., Jiménez, A. F., \& Palomo, A. (2011). New cements for the 21st century: The pursuit of an alternative to Portland cement. Cement and concrete research, 41(7), 750-763.

Van Jaarsveld, J. G. S., Van Deventer, J. S. J., \& Lukey, G. C. (2002). The effect of composition and temperature on the properties of fly ash-and kaolinite-based geopolymers. Chemical Engineering Journal, 89(1-3), 63-73. 